\title{
Analysis on the Coordinated Development Mechanism of Regional Economy
}

\author{
Yanning Wei \\ Xi’an International University, Xi’an, Shaanxi, 710077
}

Keywords: Regional Economy, Coordinated Development, Social Development

\begin{abstract}
The coordinated development of regional economy is the prerequisite for the sustained and efficient operation of the national economy. Although there are many discussions on the coordinated development of China's regional economy, there are still deficiencies in theoretical research. The significance of this paper is to systematically explore the connotation, dynamic mechanism and evaluation indicators, standards and quantitative methods of coordinated development of regional economy, thus providing a theoretical basis for the formulation of relevant national policies.
\end{abstract}

\section{Introduction}

The formulation and implementation of the coordinated development strategy of regional economy is an objective requirement for the development of China's regional economy to the present stage. Since the founding of the People's Republic of China, China's regional economic development strategy has experienced a historical evolution from a balanced development strategy to a non-equilibrium development strategy to a non-equilibrium coordinated development strategy. Before the reform and opening up, China implemented a balanced development strategy. The implementation of this strategy played a positive role in expanding the space for China's productive forces, accelerating the process of urbanization and industrialization in the central and western regions, and changing the pattern of serious imbalances in the old China's economy. . However, it also artificially suppressed the development of the eastern coastal areas, resulting in a double loss of national economic efficiency and social equity. Since the 1980s, on the basis of rethinking the balanced development strategy of the regional economy since the founding of the People's Republic of China, the state has made major adjustments to the resource allocation and regional economic development strategies, from emphasizing the balanced development of regional economies to the overall development of the national economy and macroeconomics. Benefits, emphasizing the full play and utilization of regional advantages, especially the geographical advantages and economic and technological advantages of the eastern coastal areas, that is, the implementation of the regional economic imbalance development strategy focusing on the eastern coastal areas. The "unbalanced development" strategy has enabled the eastern region to develop rapidly in the central and western regions, and the eastern region has taken the lead in development, which has greatly promoted the overall progress of China's economy and society and greatly enhanced China's comprehensive strength.

\section{Connotation and characteristics of coordinated development of regional economy}

According to the system theory, no matter how the region is divided or the size of the region, the regional economy is the subsystem or component of the entire national economy. Therefore, the above analysis of system coordination is fully applicable to regional economic systems. So, what is the content of coordinated development of the regional economy? In other words, in the economic development, what aspects of the region need to be coordinated? Obviously, as a complex system, there is a lot of content for the coordinated development of the regional economy. As mentioned above, the coordinated development of the regional economy can be understood from different angles, and each aspect thus obtained, as long as it can be relatively independent, can and should constitute a content of the coordinated research on regional economic development. However, on 
the whole, it can be roughly divided into two aspects: regional total structure coordination and regional economic relationship coordination.

(1) Coordination of regional aggregate structure, that is, coordination of regional development levels and coordination of development speed. The coordinated development of the regional economy requires that the ratio of the total amount of the region should balance the efficiency goal with the balanced goal, and achieve a virtuous cycle of regional economic development. In order not to excessively pursue the high speed of economic growth and the optimization of investment benefits, the minimum balance should be ignored, and the regional balance cannot be forced at the expense of the speed and efficiency of national economic growth. The correct choice is to maintain the gap between the inter-regional economic levels within the scope of maintaining a higher rate of national economic growth, higher efficiency, and ensuring national unity and social stability. (2) Coordination of regional economic relations. The coordination of regional economic relations mainly includes two aspects: First, the coordination of inter-regional industrial structure. The coordination of regional industrial structure means that the formation and adjustment of inter-regional industrial structure should be carried out in accordance with the principle of rationally organizing regional division of labor and giving play to regional advantages. It is necessary to abandon the establishment of a self-contained, independent and complete regional national economic system and industrial system. The idea is to eliminate the phenomenon of serious regional industrial structure assimilation, guide and promote the rational flow and allocation of resource elements, and form a reasonable inter-regional industrial structure and division of labor system. Second, the coordination of inter-regional flows of factors. That is, efforts should be made to eliminate various obstacles that hinder the flow of production factors in the region. By actively cultivating regional markets and national unified markets, establish and improve market rules and regulations, improve market mechanisms, regulate market behaviors of economic entities, and realize inter-regional commodities and production factors. Free and reasonable flow.

\section{The mechanism of the market's role in the coordinated development of regional economy}

For the convenience of research, the first hypothesis is given here: a country is still divided into two regions, the first region and the latter region. (1) The first-region regional economy is relatively developed, the development funds are abundant, but the labor force is lacking; the post-regional economy is relatively backward and the funds are lacking, but the production factors such as natural resources, energy raw materials and labor are rich. In addition, the other conditions of the two regions are the same. (2) Elements and commodities are freely mobile, the scale returns are unchanged, and the marginal returns of production factors are declining. The role of the market in the coordinated development of the regional economy essentially relies on market mechanisms to achieve the distribution and combination of resources, that is, through the supply and demand mechanism, the price mechanism and the competition mechanism are interconnected and interacted. That is, resources are allocated by freely transferring resources caused by changes in market price signals. The price signal reflects the relationship between supply and demand and is the result of the supply and demand mechanism. The competition mechanism is initiated by the movement of the price mechanism. The development of the competition relationship forms the process of resource allocation, which in turn regulates the relationship between supply and demand. Make reasonable allocations and have an impact on regional economic development. The following is an analysis of the role of the market in promoting the four "marks" of coordinated regional economic development.

Under mature market conditions, market regulation will closely link economic ties between regions. This is because, first, regional economic linkages or interactions between regions require three preconditions, namely, complementarity, accessibility and interference opportunities between regions. Under mature market conditions, factors and commodities are freely flowing, and there are no administrative or trade barriers between regions. If other conditions are certain, it means higher accessibility between regions. Second, due to the differences between natural endowments and social resources, there is objective complementarity between the pre-emptive and post-development 
areas, that is, there is mutual demand. Obviously, the free flow of factors and commodities can, to a certain extent, satisfy the needs of both parties, thereby increasing the degree of interdependence between the pre-emptive and post-development regions. Third, under mature market conditions, the production factors will Seeking to deploy in a larger space to increase its utilization rate, that is, ample development funds in the first-period area will flow to the post-development area, while the rich labor resources in the post-development area will flow to the pre-emption area, so that from the perspective of material production The two regions are closely linked together. Finally, the free flow of elements and commodities across regions reduces the cost of regional division of labor and promotes the division of labor between regions, thus promoting the deepening of economic exchanges between regions.

\section{The mechanism of the cross-regional expansion of enterprises on the coordinated development of regional economy}

Cross-regional expansion of enterprises must seek to allocate resources in a larger space to fully utilize the comparative advantages of different regions, thus promoting a reasonable division of labor between regions. The cross-regional expansion of Guangdong and Hubei industrial listed companies also shows their role in promoting the rationalization of regional division of labor. This is mainly reflected in the adjustment of the existing production to the local production through cross-regional expansion. There are two specific ways: First, according to changes in the environment, shrinking production of products that are not suitable for local resources, and even gradually withdrawing from the production field, while expanding the operation of other products; second, products that are not suitable for local resources. Production is gradually shifting to the central and western regions with resource advantages to reduce production costs and expand the sales market. For example, due to the reduction of domestic cotton production, the price of cotton and its textile raw materials has risen, and the tax reform has caused an increase in the tax burden of the textile industry. On the other hand, the domestic and international textile market has further weakened, which has made the domestic textile industry difficult. In Shenzhen, the labor-intensive industry of the textile industry is more affected by the cost of cheap labor and ancillary services in the Mainland. Faced with changes in the market environment and other factors, Shenzhen Textile (Group) Co., Ltd. vigorously adjusted the production structure. On the one hand, it contracted the production of textiles in Shenzhen, and carried out diversified operations, expanding to real estate, hotels and other industries, such as joint ventures. Invested in Chengdu Gangpeng Real Estate Development Co., Ltd., Chengdu Royal Entertainment City Co., Ltd., Jiangxi Jiujiang Hongfa Real Estate Company, etc.; on the other hand, the transfer of textile production to the post-development area with the advantage of cheap labor and raw materials, the company's technology, The marketing advantage is combined with local policies and cost advantages to improve product competitiveness. For example, it has invested in Sichuan Renshou Xingda Cotton Textile Co., Ltd. and Jiangxi Yuli Line Industry Co., Ltd. At present, the company is gradually shifting from the traditionally competitive field to the high-tech, high value-added, high-end brand. A similar situation exists in the cross-regional expansion of post-development regional enterprises. For example, Huagong Technology Industry Co., Ltd. and Hubei Baike Pharmaceutical Co., Ltd. respectively expanded to Guangdong, Beijing and Shandong to take advantage of local technological advantages; The company invested in research and development and manufacturing in Nanjing.

Regarding the overall efficiency of regional economic development. As mentioned earlier, cross-regional expansion of the business optimizes resource allocation, thereby increasing the overall efficiency of regional economic development. The cross-regional expansion of enterprises has also brought significant benefits to both sides of the region. In order to reflect the contribution of cross-regional expansion of enterprises to the economic development of the post-development area and the first-generation area, two indicators were selected here, namely the asset size of the expansion project and the net profit created in the current year. Of course, the size of the assets of the expansion project is not the total contribution to the target regional economy, or that it is only a small part of its actual contribution. Because it does not consider the role of investment in local 
employment, and the multiplier effect of economic growth caused by industry linkages. By the same token, net profit only roughly reflects the contribution of cross-regional expansion enterprises to the economic growth of their region.

The narrowing of the gap in regional economic development. Although the existing statistics can not directly reflect the effect of cross-regional expansion of enterprises in Guangdong Province and Hubei Province on narrowing the economic development gap between the post-development region and the pre-development region, the obvious fact is that the two regions have mutual expansion across the region. It released the development potential of the late-developing regional enterprises, stimulated its vitality, increased the development funds, senior talents, advanced technology and management experience of the late-developing regions, and also catalyzed the change of the post-regional system, thus giving it a post-development The advantage laid the foundation. The aforementioned analysis of the scale of assets expansion and net profit indicators of enterprises also indicates to a certain extent that the cross-regional expansion of enterprises can greatly promote the development of the post-regional economy, which is conducive to narrowing the economic development gap between them and the starting regions.

\section{Conclusion}

The mechanism by which the market promotes the coordinated development of the regional economy. First, the free flow of elements and commodities has made the regions more accessible, and the mutual needs of both parties have been met, thus linking the two closely together in the perspective of material production and improving the region. The degree of interdependence; second, the free flow of elements and commodities, enabling resources to be optimally allocated in a larger space, and a sound market system, which also reduces the transaction costs of regional division of labor, thereby promoting regional Reasonable division of labor; Third, the free flow of population and labor, the expansion of market space by pre-emptive regional enterprises, and the induction of government behavior, which promoted the narrowing of regional economic development gap; Fourth, the free flow of factors changed the region. The relationship between supply and demand of factors, which in turn causes changes in factor prices. In this way, under the influence of the supply and demand mechanism and the price mechanism, not only the two sides can benefit from it, but also improve the overall efficiency of regional economic development because of the optimal allocation of factors.

\section{References}

[1] Demurger S., Saches, JD, Woo, WT, Bao, Shuming, Chang, GH The Relative Contributions of Location and Preferential Policies in China's Regional Development: Being in the Right Place and having the Right Incentives [J]. Econ, 2002, Rev., (13): 444-465.

[2] Feng Y., Genna GM Regional Integration and Domestic Institutional Homogeneity: a Comparative Analysis of Regiol Integration in the Americas, Pacific Asia and Western Europe [J]. Review of International Political Economy, 2003, (5): 278-309 .

[3] Golley J. Regional Patterns of Industrial Development during China's Economic Transition [J]. Econ. Transition, 2002, 10(3): 761-801.

[4] Lu M. and Wang E. Forging Ahead and Falling Vehind: Changing Regional Inequalities in Post Reform China [J]. Growth and Change, 2002, 33(1), 42-71.

[5] Sun H. and Parikh A. Exports, inward Foreign Direct Investment (FDI) and Regional Economic Growth in China [J]. Reg. Studies, 2001, 35(3), 187-196. 